\title{
Characteristics of Childhood Steroid-Induced Glaucoma Patients in National Eye Center, Cicendo Eye Hospital, Bandung, Indonesia from 2007 to 2011
}

\author{
Indri Nurul Badriyah, ${ }^{1}$ Irawati Irfani, ${ }^{2}$ Lulu Eva Rakhmilla ${ }^{3}$ \\ ${ }^{1}$ Faculty of Medicine Universitas Padjadjaran, ${ }^{2}$ Department of Ophthalmology Faculty of \\ Medicine, Universitas Padjadjaran/Cicendo Eye Hospital Bandung, ${ }^{3}$ Department of Obstetry and \\ Gynecology Faculty of Medicine Universitas Padjadjaran/Dr. Hasan Sadikin General Hospital \\ Bandung
}

\begin{abstract}
Background: The prevalence of children's blindness in developing countries is still high especially in Asian countries. This children's blindness influences their motoric, social and emotional developments and their chances to get education. One of the causes is steroid-induced glaucoma. The aim of the study was to identify the characteristics of childhood steroid-induced glaucoma in National Eye Center, Cicendo Eye Hospital, Bandung, Indonesia.

Methods: A descriptive study was conducted to 22 medical records of childhood steroid-induced glaucoma patients in National Eye Center, Cicendo Eye Hospital Bandung from 2007-2011. The inclusion criterias were medical records contained complete demographic (age, sex, address and socioeconomic status), clinical (visual acuity, intraocular pressure, cup-disc ratio, underlying eye disease, working diagnosis, treatment and patient's compliance to follow up) and risk factor (type and route of administration of steroid and duration of steroid usage).

Results: Majority of patients were boys (73\%), aged 4-7 years old (41\%), from Bandung (55\%), with moderate socioeconomic condition (73\%). Most of the patients experienced blindness (64\%), intraocular pressure around $20-30 \mathrm{mmHg}(33 \%)$, cup-disc ratio above $0.4(77 \%)$. The underlying eye disease was conjunctivitis vernalis (95\%). They were treated by medicamentosa or trabeculectomy. The most common used steroid contained dexamethasone $(100 \%)$ for more than 1 year of usage $(64 \%)$. Patients's compliance to follow up was mostly good (59\%).

Conclusions: Most of the patients with steroid-induced glaucoma is still very young and the use of topical dexamethasone to treat conjunctivitis vernalis for a long time leads to steroid-induced glaucoma. [AMJ.2015;2(3):346-51]
\end{abstract}

Keywords: Children, conjunctivitis vernalis, dexamethasone, steroid-induced glaucoma

\section{Introduction}

The prevalence of children's blindness in developing countries is $1.0-1.5$ in 1000 children. Most of them live in Asia. ${ }^{1}$ Actually, the incident of children's blindness is not as high as incident of adult's blindness. However, the important impact is that children with blindness have much longer 'blind years' than adults do. ${ }^{1}$ Blindness in children also influences their chance to get education and to develop their talent. Moreover, blindness that occurs early in childhood interfere their motoric, social and emotional development. ${ }^{2}$

There are many causes of children's blindness, one of them is glaucoma. Compared with cataract, glaucoma becomes a more challenging public health problem, because blindness caused by glaucoma can be permanent.The incident of glaucoma can be decreased by involving the role of community. People's awareness of children's glaucoma should be increased because actually blindness caused by this disease can be prevented by early detection dan appropriate treatment.

Glaucoma can be caused by long term usage of steroid without doctor's supervision. This causes a condition called steroid-induced glaucoma. Steroid-induced glaucoma causes blindness by increasing the resistance of aqueous humor flow. ${ }^{3}$ Some types of steroid whether it is topical, oral or periocular can raise intraocular pressure and lower the facility of

Correspondence: Indri Nurul Badriyah, Faculty of Medicine, Universitas Padjadjaran, Jalan Raya Bandung-Sumedang Km.21, Jatinangor, Sumedang, Indonesia, Phone: +6285724555890 Email: indrinurulbadriyah@yahoo.com 
aqueous humor flow. The intraocular pressure of $5-6 \%$ normal population increased more than $31 \mathrm{mmHg}$ after $4-6$ week treated by topical corticosteroid. ${ }^{4}$ Children were more susceptibility to steroid than adults. ${ }^{3}$ This makes them susceptible for having steroidinduced glaucoma with blindness as the final complication.

Steroid-induced glaucoma has many important risk factors. There is an increase of intraocular pressure in children below 10 years old, who use dexamethasone or fluorometholone topical drops, two times or four times everyday. ${ }^{5}$ The increase of intraocular pressure happens after 10 days and also related to the intensity of steroid usage. ${ }^{5}$ Furthermore, gender also determines the risk for having steroid-induced glaucoma. Since the 'blind years' in children is higher than adult, steroid-induced glaucoma in children needs more attention. Therefore, this study intended to find the characteristics of the disease through secondary data from medical records in Cicendo Eye Hospital Bandung. The aim of the study was to identify the characteristics of childhood steroid-induced glaucoma in Cicendo Eye Hospital Bandung in the period of January 2007-December 2011.

\section{Methods}

A descriptive study was carried out to 22 medical records of childhood steroid-induced glaucoma patients in Cicendo Eye Hospital Bandung on the period of January 2007December 2011.

Medical records that fulfill the inclusion criteria (comprised complete demographic, clinical dan risk factor data), were included in this study, while the exclusion criteria was the medical records with incomplete data. Variables in this study were divided into three categories; there were demographic, clinical and risk factor variables. The demographic variable consisted of age, sex, address and socioeconomic status. The clinical variable consisted of visual acuity, intraocular pressure, cup-disc ratio, underlying eye disease, working diagnosis, treatment and patient's compliance to follow up. The risk factor variable consisted of type and route of administration of steroid and duration of steroid usage.

Age in this study was the age of patients when they are diagnosed with steroid-induced glaucoma. The age of the patients were stated in year and in the range of children's age in Pediatric Ophthalmology and Strabismus Outpatient Clinic in Cicendo Eye Hospital,
0-14 years old. Sex consisted of male and female. Patients's residences were the address of patients when they came to hospital. It was classified into Bandung and outside Bandung. From this data, patients were divided into referral and nonreferral patients. Patients were also grouped into moderate and low socioeconomic patients based on Jaminan Kesehatan Masyarakat and non-Jaminan Kesehatan Masyarakat (JAMKESMAS and nonJAMKESMAS). The working diagnosis was steroid-induced glaucoma either unilateral or bilateral. Treatment of this case was all of the management given to the patients either medicamentosa or surgery (trabeculectomy) on the first visit, first follow up after one month, and second follow up after three months. The visual acuity was visual acuity when patients were diagnosed with steroidinduced glaucoma, and classified based on WHO classification, into normal visual acuity $(0.33-1.0)$, visual impairment $(<0.33-0.1)$, severe visual impairment $(<0.1-0.05)$ and blind $(<0.05) .{ }^{6}$ Intraocular pressure, cup-disc ratio, underlying eye disease, type and route of steroid administration and duration of steroid usage were obtained from patients's medical records. Patients's compliance was assessed from frequency of patient to follow up. It was classified into good compliance for the patients who came to follow up in the first month and third month, moderate compliance for patients who came to follow up in either the first month or third month and poor compliance for the patients who did not come to follow up at all.

\section{Results}

There were 25 children diagnosed with steroid-induced glaucoma in Cicendo Eye Hospital from January 2007-December 2011. However, there were only 22 patients with complete characteristic data on their medical records while three other patients' medical records were incomplete, so the percentage of medical records studied was $88 \%$.

Most of the patients were boys, under 11 years old, from moderate socioeconomic status and live in Bandung. Most of the patients from Bandung came to Cicendo Eye Hospital without referral from other health facilities, but on the other hand, patients from outside Bandung were patients referred by other health facilities before coming to Cicendo eye Hospital. Moreover, the clinical condition prior to steroid application was conjunctivitis vernalis. 
Table 1 Characteristic of Childhood Steroid-Induced Glaucoma Patients

\begin{tabular}{|c|c|c|}
\hline Characteristics & Number (n) & Percentage (\%) \\
\hline \multicolumn{3}{|l|}{ Sex } \\
\hline Boy & 16 & 73 \\
\hline Girl & 6 & 27 \\
\hline \multicolumn{3}{|l|}{ Age (years old) } \\
\hline $4-7$ & 9 & 41 \\
\hline $8-11$ & 7 & 32 \\
\hline $12-15$ & 6 & 27 \\
\hline \multicolumn{3}{|l|}{ Socioeconomic status } \\
\hline Moderate & 16 & 73 \\
\hline Low & 6 & 27 \\
\hline \multicolumn{3}{|l|}{ Patients's Residence } \\
\hline \multicolumn{3}{|l|}{ Bandung } \\
\hline Referral Patient & 2 & 9.1 \\
\hline Nonreferral Patient & 10 & 45.5 \\
\hline \multicolumn{3}{|l|}{ Outside Bandung } \\
\hline Referral Patient & 8 & 36.4 \\
\hline Nonreferral Patient & 2 & 9.1 \\
\hline \multicolumn{3}{|l|}{ Working Diagnosis } \\
\hline Unilateral & 5 & 23 \\
\hline Bilateral & 17 & 77 \\
\hline \multicolumn{3}{|l|}{ Visual Acuity } \\
\hline Normal & 8 & 21 \\
\hline Visual impairment & 4 & 10 \\
\hline Severe visual impairment & 2 & 5 \\
\hline Blind & 25 & 64 \\
\hline \multicolumn{3}{|l|}{ Intraocular Presure } \\
\hline 20-30 mmHg & 13 & 33 \\
\hline $31-40 \mathrm{mmHg}$ & 9 & 23 \\
\hline$>40 \mathrm{mmHg}$ & 6 & 15 \\
\hline Palpation $\mathrm{N}+$ & 10 & 26 \\
\hline Hard to assess & 1 & 3 \\
\hline \multicolumn{3}{|l|}{ Cup-disc Ratio } \\
\hline $0.3-0.4$ & 3 & 8 \\
\hline$>0.4$ & 30 & 77 \\
\hline Hard to assess & 6 & 15 \\
\hline \multicolumn{3}{|l|}{ Underlying Eye Disease } \\
\hline Conjunctivitis vernalis & 21 & 95 \\
\hline Uveitis Anterior & 1 & 5 \\
\hline Type of steroid: Dexamethasone & 22 & 100 \\
\hline Route of Administration: Topical & 22 & 100 \\
\hline
\end{tabular}


Indri Nurul Badriyah, Irawati Irfani, Lulu Eva Rakhmilla: Characteristics of Childhood Steroid-Induced 349 Glaucoma Patients in National Eye Center, Cicendo Eye Hospital, Bandung, Indonesia from 2007 to 2011

Table 1 Characteristic of Childhood Steroid-Induced Glaucoma Patients

\begin{tabular}{|c|c|c|c|}
\hline & Characteristics & Number (n) & Percentage (\%) \\
\hline \multicolumn{4}{|c|}{ Duration of steroid usage } \\
\hline$<6$ months & & 3 & 14 \\
\hline 6-12 months & & 5 & 22 \\
\hline$>12$ months & & 14 & 64 \\
\hline \multicolumn{4}{|c|}{ Patient's compliance } \\
\hline Good & & 13 & 59 \\
\hline Moderate & & 7 & 32 \\
\hline Poor & & 2 & 9 \\
\hline
\end{tabular}

The treatment of steroid-induced glaucoma in children patients at Cicendo Eye Hospital when diagnosed, was followed up after one month and followed up after three months (Table 2).

\section{Discussions}

Boys are the most common patients in this study. Actually, there is no gender predilection in this disease. Based on the literature, steroidinduced glaucoma can occur both in boys and girls ${ }^{4}$, it is more related to the underlying eye disease. In this study, most of underlying eye disease of the steroid-induced glaucoma is conjunctivitis vernalis suffered mostly by boys aged 3-16 years old. ${ }^{7}$

Based on the age of patients, childhood steroid-induced glaucoma mostly occurs in age 4-7 years old. This study is appropriate with a literature which states that there is an increase of intraocular pressure in children under 10 years old treated by topical dexamethasone. ${ }^{8}$

In this study, steroid-induced glaucoma patients mostly come from Bandung (55\%). Cicendo Eye Hospital is national referral hospital located in Bandung. It is easier to be accessed by patients who live in Bandung, although there are some patients referred from another city. From the referral information, most patients who come from outside Bandung are referred by a general practitioner in the district hospital, primary health care or private practice of a general practitioner. It shows that the referral system of this case in the district area outside Bandung is good. Most of the general practitioners understand that this case should be referred to the ophthalmologist immediately. Meanwhile, most patients who come from Bandung are not referral patients because the Cicendo Eye Hospital is easier to be accessed by them, although patients who come to this national referral hospital should be 'referral patients'.

There are 17 patients (77\%) who have bilateral glaucoma and there are 5 patients (23\%) who have unilateral glaucoma. So, in this study, there are 39 eyes (89\%) with steroid-induced glaucoma, while other 5 eyes $(11 \%)$ are normal. In this study, there are 25 blind eyes (64\%), with visual acuity $<3 / 60$. This is appropriate with literature which states that mostly patients complain about the decreasing of visual acuity when intraocular pressure begin to raise and damage the optic nerve. ${ }^{9}$ This study shows that most of the

Table 2 Treatment of Steroid-Induced Glaucoma Patients

\begin{tabular}{lcccccc}
\hline \multirow{2}{*}{ Treatment } & \multicolumn{7}{c}{ n(\%) } \\
\cline { 2 - 6 } & Initial Therapy & Follow up on month 1 & Follow up on month 3 \\
\hline Antiglaucoma medicamentosa & 18 & $(82 \%)$ & 7 & $(32 \%)$ & 11 & $(50 \%)$ \\
$\quad$ Topical & 4 & $(18 \%)$ & 2 & $(9 \%)$ & 1 & $(5 \%)$ \\
$\quad$ Combination (topical and oral) & 0 & $(0 \%)$ & 4 & $(18 \%)$ & 1 & $(5 \%)$ \\
Surgery (trabeculectomy) & 0 & $(0 \%)$ & 6 & $(27 \%)$ & 2 & $(9 \%)$ \\
Without medicamentosa antiglaucoma & 0 & $(0 \%)$ & 3 & $(14 \%)$ & 7 & $(32 \%)$ \\
Did not follow up & & & & & & \\
\hline
\end{tabular}


patients came to the doctor only when they realized that there was something wrong with their vision, even they have had blindness.

Patients in this study mostly have intraocular pressure around 20-30 $\mathrm{mmHg}$ (33\%). The increasing of intraocular pressure is appropriate with the literature which states that there is an increasing $5-10 \%$ intraocular pressure in general population who use steroid for 6 weeks. ${ }^{10}$ Cup-disc ratios in this study are mostly above 0.4 . Literature states that patients diagnosed with glaucoma have higher cup-disc ratio both vertically and horizontally. ${ }^{11}$ This is appropriate with this study that showed an increasing cup-disc ratio in patients.

The most common underlying eye disease for these cases is conjunctivitis vernalis. Conjunctivitis vernalis is a chronic inflammation of conjunctiva that often happened in boys of 3-16 years old. ${ }^{12}$ Medication for the disease is symptomatic, by giving topical steroid drops like prednisolone or dexamethasone. ${ }^{12}$ Uncontrolled steroid medication for these cases can cause the increasing of patient's intraocular pressure.

There are some kinds of steroid that are used by 22 children diagnosed with steroid-induced glaucoma. They are $\mathrm{Xitrol}^{\mathrm{TM}}$, Polydex $^{\mathrm{TM}}$, Polydemycin ${ }^{\mathrm{TM}}$ and Corthon ${ }^{\mathrm{TM}}$. Each of them contains a potent steroid. Most of the patients in this study use $\mathrm{Xitrol}^{\mathrm{TM}}$. Xitrol ${ }^{\mathrm{TM}}$ is an eye drop containing dexamethasone $0.1 \%$, neomycin sulphate $3.5 \mathrm{mg} / \mathrm{mL}$ and polymyxin B sulphate $6000 \mathrm{IU} / \mathrm{mL}$. Xitrol ${ }^{\mathrm{TM}}$ is indicated for eye inflammation, acute or chronic conjunctivitis, blepharoconjunctivitis, keratoconjunctivitis, superficial keratitis and other eye inflammation disease. The dosage is 4-6 times a day, 1-2 drops. Xitrol ${ }^{\mathrm{TM}}$ contains dexamethasone which is group of sintetic long acting glucocorticoid. Another study states that dexamethasone and betamethasone both topical and oral are more potent to cause glaucoma compared with medrisone and prednisolone. ${ }^{13}$ This is proved by this study, that most of the steroid-induced glaucoma patients used dexamethasone.

All of the routes of steroid administration of patients in this study were topical administration through eye drops. Topical steroid administration is the most common cause of steroid-induced glaucoma. This study is appropriate with a literature which states that topical steroid therapy often causes the increasing of intraocular pressure than oral administration. ${ }^{14}$

In this study, there were 14 patients (64\%) who used steroid for more than 1 year. The duration of steroid usage influenced the risk of steroid induced glaucoma incidence. These data were appropriate with the study held by Saadia Farooq and Aslam Malik ${ }^{15}$ who states that increasing of intraocular pressure can happen only in 2-6 weeks after steroid usage. Based on this study, patients's compliance to follow up is good. There were 13 patients (59\%) who follow up twice, on the first and third month. The compliance to follow up is very important to keep the disease in control and does not getting worse. ${ }^{16}$ Therefore, patients were suggested to follow up regularly.

Treatment for patients in this study on the initial therapy was topical medicamentosa with Timolol ${ }^{\mathrm{TM}}$ and Dorzol $^{\mathrm{TM}}$. Timolol ${ }^{\mathrm{TM}}$ is nonselective beta aderenergic receptor blocker on eye and contains active substance oftimolol maleate. This drug is used to treat ocular hypertension by decreasing amount of aqueous humor that secreted by ciliary body. Furthermore, this drug causes constriction of blood vessels that supply ciliary body and decreases the amount of fluid filtrated by blood vessel to produce aqueous humor. While Dorzol $^{\mathrm{TM}}$ is a group of carbonic anhidrase inhibitor, and contains active substance of dorzolamide hydrochloride. It inhibits carbonic anhidrase II in ciliary processes on eye by slowing bicarbonate ion formation. Thus, it also has the same function that is lowering intraocular pressure by decreasing aqueous humor production. Oral therapies given to the patients were potassium L-aspartate and acetazolamide.

In this study, Timolol ${ }^{\mathrm{TM}}$ and Dorzol ${ }^{\mathrm{TM}}$ were given in the first time when the patients were diagnosed with steroid-induced glaucoma. These drugs were given on the initial therapy because the increasing of intraocular pressure in many cases can be decreased only by stopping the steroid or by giving topical antiglaucoma. ${ }^{8}$ However, on the next follow up, some patients still had high intraocular pressure so that trabeculectomy was needed.

Some patients were not given antiglaucoma therapy anymore on the next follow up because their intraocular pressures were getting better. These patients were treated only for their underlying eye disease. The underlying eye disease was treated by Potassium Pemirolast $0.1 \%$ and Flurometholone $0.1 \%$. Both of the drugs inhibit allergic process in the eye.

Another variable that can be studied for steroid-induced glaucoma in children is thevisual field examination. It was held to know the specific location of patient's visual 
field loss. This was hard to do possibly because the children were less cooperative for this examination.

In this study, there was a bias information about the frequency of steroid usage by the patients. Steroid usage duration was based on anamnesis of medical records, while the frequency of steroid usage along the duration is unknown. There were some patients who did not come to follow up so the data of patient's follow up is incomplete. These conditions were the limitations of the study

Actually, childhood steroid-induced glaucoma can be prevented. A good follow up of the patients who used long term topical steroid is really suggested. Therefore, parents should be educated about the risk of long term steroid usage for their children. The doctors should give a very clear informed consent to the parents, so that the parents will realize the risk of long term steroid usage without doctor's supervision and do the follow up regularly. Furthermore, the drugs potential to cause glaucoma should be only prescribed when the patient has an indication. For the long term usage, it can be started with less potential steroid and the intraocular pressure should be evaluated strictly.

Based on the data of this study, most of steroid-induced glaucoma patients were accompanied by high risk condition of blindness.

\section{References}

1. Kementerian Sosial Republik Indonesia. Pencapaian Target MDGs Keempat dan Booming Kebutaan Anak. Jakarta; Kementerian Sosial Republik Indonesia; 2012.

2. Gilbert C, Awan H. Blindness in children. BMJ. 2003;327(7418):760-1.

3. Jones R, Rhee DJ. Corticosteroid-induced ocular hypertension and glaucoma. Curr Opin Ophthalmol. 2006;17(2):163-7.

4. Albert DM, Jakobiec FA. Principles and practice of ophthalmology. 2nd ed. New
York: W. B. Saunders Company; 1994.

5. Stamper RL, Lieberman MF, Drake MV. Becker-Shaffer's diagnosis and therapy of the glaucomas. 8th ed. New York: Mosby Elsevier; 2009.

6. WHO. Recommendations of the WHO consultation on "Development ofStandards for Characterization of Visual Loss and Visual Functioning". San Francisco:WHO. 2003.

7. Barney NP. Epidemiology and genetics of ocular allergy. World Allergy Organization. [Cited 2012 November 10]. Available from: http://www.worldallergy.org/ educational_programs/world_allergy_ forum/berlin/barney.php

8. Cohen A. Steroid induced glaucoma. In: RumeltS, editor. 2011 Glaucoma -basic and clinical concepts. New York:InTech; 2011.

9. Zimmerman TJ, Kooner KS, editors. Clinical pathways in glaucoma. New York: Thieme; 2001.

10. Blanco AA, Costa VP, Wilson RP. Handbook of glaucoma. London: Martin Dunitz; 2002.

11. Morrison JC, Freddo TF, Toris CB. Clinical evaluation of the optic nerve head. In: Morrison JC, Pollack IP, editors. Glaucoma science and practice. New York: Thieme; 2003. p. 90-93.

12. Hall A, Shilio B. Vernal keratoconjunctivitis. Community Eye Health. 2005;18(53):768.

13. Mohan R, Muralidharan AR. Steroid induced glaucoma and cataract. Indian J Ophtalmol. 1989;37(1):13-6.

14. Allingham RR, Damji KF, Freedman S, Moroi SE, Shafranov G, editors. Shield's text book of glaucoma. Philadelphia: Lippincott William and Wilkins; 2005.

15. Farooq S, Malik A. Evaluation and management of steroid induced glaucoma in vernal keratoconjunctivitis patients. Pak J Ophthalmol. 2007;23(1):1-4

16. Jackson A. Understanding and living with glaucoma. Glaucoma Research Foundation. 2012 [Cited 2012 November 21]. Available from: https://www.glaucoma.org/GRF_ Understanding_Glaucoma_EN.pdf. 